Bangladesh J. Zool. 48(1): 203-209, 2020

\title{
FIRST REPORT OF FUNGUS SCOPULARIOPSIS BREVICAULIS FROM FRESH WATER DRY SHRIMP IN BANGLADESH
}

\author{
Ismot Ara*, Roksana Sultana, Ismath Jahan Chanda and Nuhu Alam ${ }^{1}$ \\ Department of Zoology, Jahangirnagar University, Savar, \\ Dhaka-1342, Bangladesh
}

Present study was conducted to find out fungal pathogen associated with dry shrimps. Scopulariopsis brevicaulis, was identified through morphological characterization based on mycelium, conidia, colony features as well as molecular characterization using internal transcribed spacer (ITS) region of rDNA. The $612 \mathrm{bp}$ ITS region was amplified using ITS4 and ITS5 primers and sequenced. To the best of our knowledge, presence of mold fungus, Scopulariopsis brevicaulis in dry shrimps is the first report in Bangladesh. Phenotypic traits and molecular characterization assured the fungus identity. Phylogenetic tree was generated with ITS sequence data by maximum likelihood, neighbor-joining and maximum parsimony and demonstrates the position of Scopulariopsis brevicaulis under the family- Microascaceae.

Bangladesh is one of the most suitable countries in the world for freshwater shrimp farming because of its favorable weather and temperature (Ahmed and Garnett 2010). The shrimp industry has gained an important place in the national economy. Shrimp has high quality protein, unsaturated essential fatty acids, minerals, and water soluble and fat soluble vitamins, to maintain good health (Boonsumrej et al. 2007). Air-drying and sun-drying are the most common methods in preserving fish due to its low cost and easy process. Dried shrimps are very popular in our country. It can also be kept for a long period of time because it underwent preservation. Thus, it is important for the consumers to know if there is a health risk from the consumption of dried shrimp (Bernal et al. 2018).

Scopulariopsis brevicaulisis a nondermatophytic mold found in soil as saprophytes are associated with invasion of nails and causes onychomycosis in

\footnotetext{
*Author for correspondence: <ismotzool@yahoo.com>, ${ }^{1}$ Laboratory of Mycology and Plant Pathology, Department of Botany, Jahangirnagar University, Savar, Dhaka-1342, Bangladesh

(C)2019 Zoological Society of Bangladesh DOI: https://doi.org/10.3329/bjz.v48i1.47889
} 
human (Lee et al. 2012). Fredrick et al. (2015), reported twenty one different fungal species viz. Fusarium moniliformis, Absidia sp., Mucor sp., Penicillium sp., Aspergillus fumigatus, A. terreus, Aspergillus flavus, A. oryzae, Trichoderma sp.,

Geotricus candidum, A. sulphureus, A. terricola, A. awamori, A. flavipes, A. versicolor, A. tamari, Euroteum sp., Alternaria sp., A. parasiticus, A. sydowii and A. ochraceous in dried fish samples from South East Coast of India dried fish markets. The fungi, Aspergillus, Absidia, Penicillium, Mucor and Fusarium as well as Chrysosporium, Cladosporium, Epidermophyton, Microsporum, and Trichophyton, are classified as molds (Atapattu and Samarajeewa 1990).

There was no record of fungal inoculums-Scopulariopsis brevicaulis associated with dry fish from Bangladesh. Therefore, the present experiment was attempted to identify mold infected dry shrimp fungus through both morphological and molecular characterizations.

Sample collection: Fresh water dry shrimps were collected from dry fish whole sale market at Savar, Dhaka with aseptic condition using sterile polyethylene bags (Fig. 1). After collection these samples were brought to the Limnology and Fishery Sciences Laboratory of the Department of Zoology, Jahangirnagar University (JU), Savar, Dhaka-1342. Fungi isolation, identification and pure culture experiments were conducted in the Laboratory of Mycology and Plant Pathology, Department of Botany, JU.

Fungus isolation: Fungus was isolated through tissue planting method. Infected parts of dry shrimp were cut into small pieces about $0.5 \mathrm{~cm}$ in length in such a manner so as to include both fungal infected and non-infected tissues in piece. Then sterilization was done using $\mathrm{NaOCl}(0.5 \%)$ solution for 5 minutes and rinsed with distilled water several times. Four pieces of samples were placed into potato dextrose agar (PDA) medium and were incubated under 12/12 hours dark and light condition at $25 \pm 2{ }^{\circ} \mathrm{C}$ for 10 days. Mycelial growth of growing fungus colony was transferred to fresh PDA plates as well as PDA slants to obtain a pure culture. The pure culture of the isolated fungus was identified microscopically using standard methods (Sikder et al. 2019).

Molecular identification: After microscopic examination, molecular characterization was done with the help of commercial service provided by Invent Technology, Dhaka, Bangladesh. Fungus genomic DNA samples were extracted using the Maxwell Cell Kit (AS1030, Promega, USA). The primer ITS4 (5'-TCCTCCGCTTATTGATATGC-3') and ITS5 (5'-GGAAGTAAA AGTCG TAACAAGG-3') were used for the PCR reaction (Alam et al. 2009). The PCR 


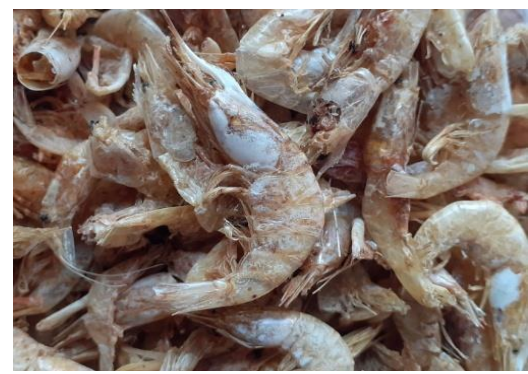

Fig.1. Fresh water dry shrimps from dry fish whole sale market of Savar, Dhaka for present study.

reaction was performed with $20 \mathrm{ng}$ of genomic DNA as the template in a 25- $\mu \mathrm{l}$ reaction mixture having a LA Taq (TAKARA BIO INC, Japan). The thermal cycle was performed with activation of Taq polymerase at $94^{\circ} \mathrm{C}$ for 1 minute; 35 cycles of $94^{\circ} \mathrm{C}$ for $30 \mathrm{Sec}, 55^{\circ} \mathrm{C}$ for $30 \mathrm{Sec}$, and $72^{\circ} \mathrm{C}$ for 5 minutes each; finishing with a 10-minute step at $72^{\circ} \mathrm{C}$ for final extension. Amplified PCR products were electrophoresed on $1.5 \%$ agarose gel in $1 \times$ TAE buffer for $1 \mathrm{hr}$ at $100 \mathrm{~V}$ with a $1 \mathrm{~kb}$ DNA ladder as a size marker and then stained while agitated in an EtBr solution $(0.5 \% \mu \mathrm{g} / \mathrm{mL})$. The stained gels were visualized and photographed using a UV transilluminator (Kodak Image Station 4000R; Molecular imaging system, Carestream Health Inc., 150 Verona Street, Rochester, NY 14608). The Maxwell ${ }^{\circledR}$ 16 DNA Purification Kits was used to purify the amplification products (Promega, USA). The purified PCR products were sequenced bi-directionally in First BASE Laboratories Sdn Bhd (Malaysia).

DNA sequences were checked by BioEdit and MEGA6. Sequencing data were submitted to the NCBI, under accession number MN886599. A BLAST search with the ITS sequences were used to reveal the closest matching taxa. Multiple sequence alignments were done using MEGA6. Data was converted from fasta to MEGA format with Clustal W. The models of evolution were determined under the Akaike Information Criterion (AIC). The model selected was Tamura-3 parameter for analysis. Maximum likelihood (ML), Neighborjoining (NJ), and Maximum parsimony (MP) analysis were done and robustness of the branches were determined with 1000 bootstrap replicates along with maxtrees set at 1000. The number of replications was inferred using the stopping criterion. Bootstrap values greater than $60 \%$ were accepted (Tamura et al. 2013).

The isolated colonies are fast growing, varying in colour from white, cream, grey, buff to brown and black, but are predominantly light brown on PDA medium. Microscopic morphology shows chains of single-celled conidia 
produced in basipetal succession from a specialized conidiogenous cell called an annellide. The youngest conidium is at the basal end of the chain. The conidia are thick walled, round to rough or spiny, globose to pyriform, usually truncate, with a rounded distal portion, smooth to rough and hyaline to brown in colour (Fig. 2). Based on these phenotypic traits, the isolated fungus seems to be Scopulariopsis brevicaulis. The asexual structures, such as conidia, shape and size, can often show highly plastic characters, making identification challenging. For sexual states (teleomorphs), ascomata are not often produced in culture, thus making it difficult to identify them based solely on morphology. As a consequence, polymerase chain reaction (PCR) and DNA sequence-based methods have emerged for identifying species within the mega diverse fungi. Molecular characterization can ensure the position of the isolated fungus from dry shrimps.
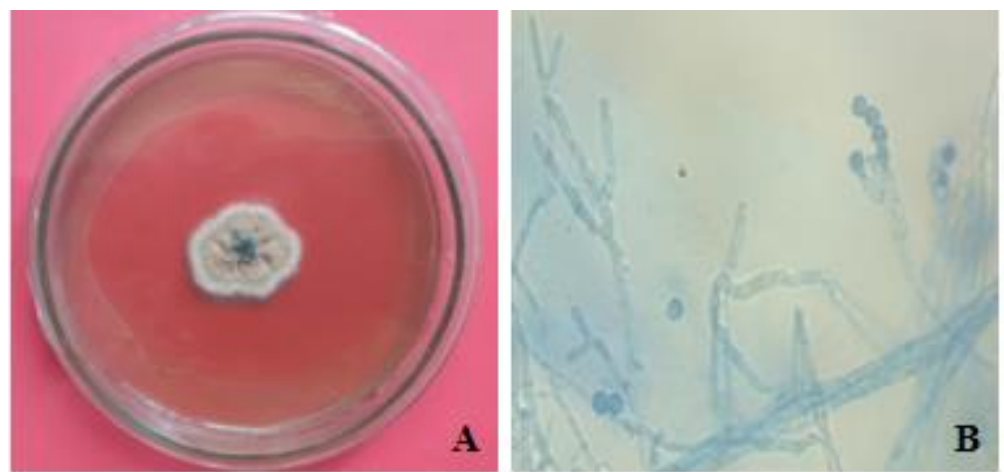

Fig. 2.Morphological characteristics of Scopulariopsis brevicaulis. A: Vegetative growth of $S$. brevicaulis on PDA medium, B: Microscopic view of conidia and conidiophores and mycelium of S. brevicaulis (40 X 10x)

For molecular identification, the ITS region of $612 \mathrm{bp}$ was amplified using ITS4 and ITS5 primers and sequenced (Fig. 3). Recent molecular phylogenetic studies have demonstrated that the internal transcribed spacer (ITS) region of genomic DNA is very useful for identification of fungi at lower taxonomic levels. The internal transcribed spacer of rDNA is considered as a variable region among the species and even among the strains (Alam et al. 2010). 


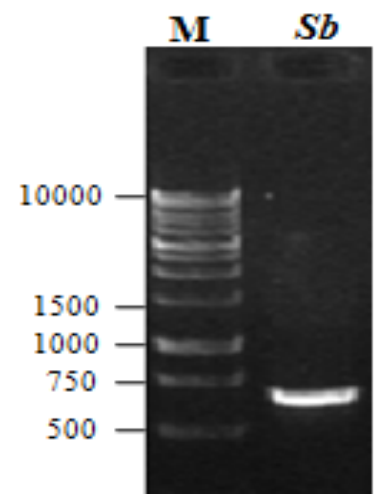

Fig. 3. PCR products of the ITS region of isolated mold $(S b)$. M, molecular size marker (1 kb DNA ladder).

Phylogenetic tree was constructed based on the nucleotide sequences of the ITS regions in thirty seven fungal taxa were downloaded from the NCBI database for phylogenic analysis. Percent homology of rDNA sequence of ITS region (MN886599) was compared with formerly identified fungi Scopulariopsis brevicaulis under accession number KP132731.1, KP132732.1, MH393393.1, EU821476.1, EU436681.1 and MH393398.1. In maximum parsimony tree, there are five different clades were found in the phylogenetic tree (Fig. 4). Reciprocal homologies of the ITS region sequences ranged from 98 to $100 \%$. The sequencing data of the selected NCBI GenBank strain (FN650641.1 Mucor indicus) was used as out group for the comparative studies on phylogenetic relationships with the selected strain of Scopulariopsis brevicaulis (MN886599). The results indicated that all the individual species of Scopulariopsis brevicaulis belong to single major cluster. Alam et al. (2010) reported that ITS sequences are genetically constant or show little variation within the species, but vary between species in a genus. Based on molecular evidence, it is clearly indicated that our studied fungus is Scopulariopsis brevicaulis under the family- Microascaceae. 


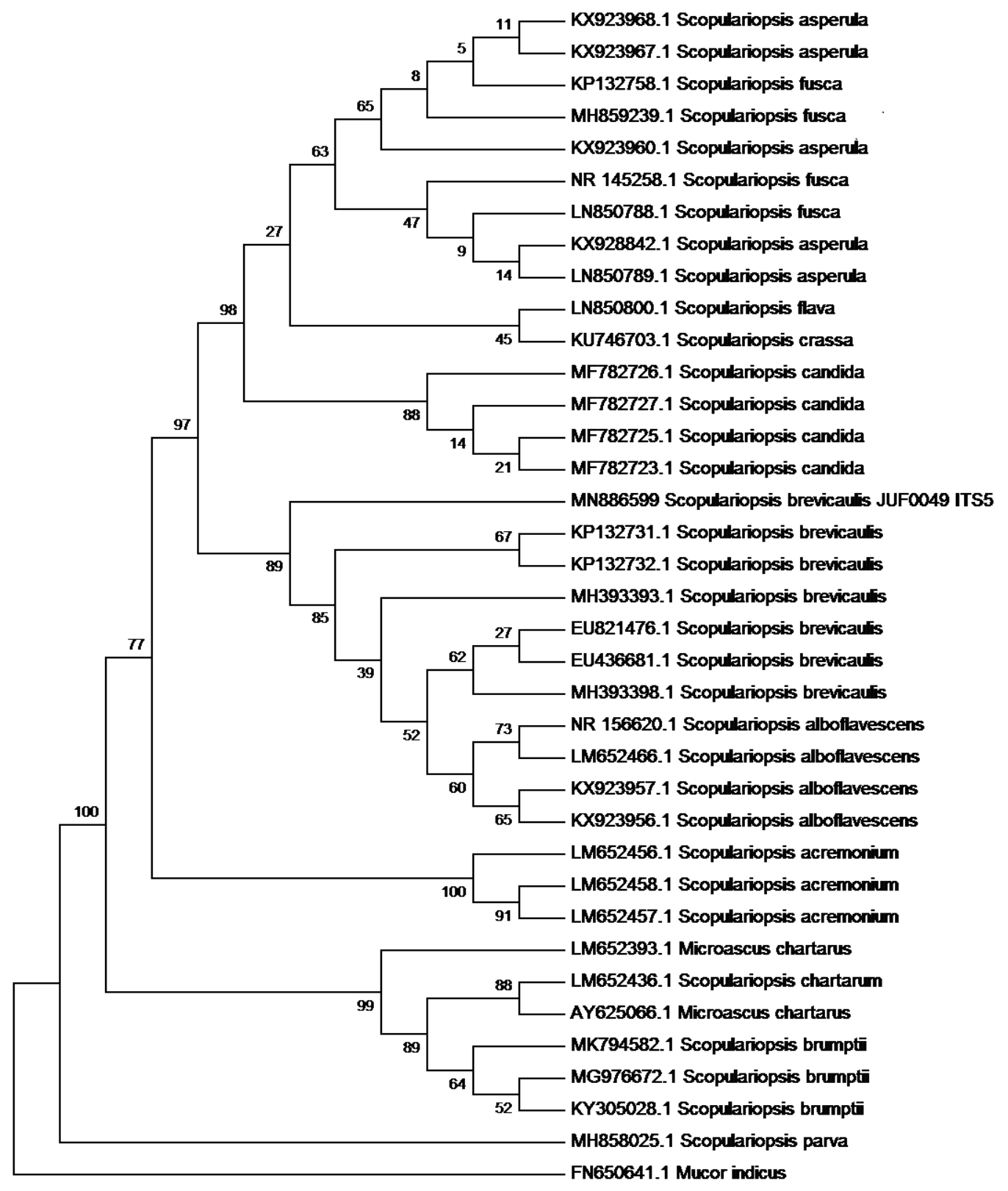

Fig. 4. Maximum likelihood tree derived from analysis of ITS sequence dataset of the studied organism with bootstrap value (Bootstrap replication=1000). Our organism (MN886599) marked with 'JUF0049'. 


\section{LITERATURE CITED}

AHMED, N. and GARNETT, S. T. 2010. Sustainability of freshwater prawn farming in rice fields in Southwest Bangladesh. J. Sustain. Agr. 34(6): 659-679.

ALAM, N., KIM, J. H., SHIM, M. J., LEE, U. Y. and LEE, T. S. 2010. Mycelial propagation and molecular phylogenetic relationships of commercially cultivated Agrocybe cylindracea based on ITS sequences and RAPD. Mycobiology. 38(2): 89-96.

ALAM, N., SHIM, M. J., LEE, M. W., SHIN, P. G., YOO, Y. B. and LEE, T. S. 2009. Phylogenetic relationship in different commercial strains of Pleurotus nebrodensis based on ITS sequence and RAPD. Mycobiology. 37(3): 183-188.

ATAPATTU, R. and SAMARAJEEWA, U. 1990. Fungi associated with dried fish in Sri Lanka. Mycopathologia. 111: 55-59.

BERNAL, K. J. P., GREÑAS, P. L. AND PATEÑA, M. A. N. 2018. Isolation and identification of fungi from dried fish and other seafoods sold in local market and selected supermarket in Batangas city. J. Allied Med. 3(1): 105-115.

BOONSUMREJ, S., CHAIWANICHSIRI, S., TANTRATIAN, S., SUZUKI, T. and TAKAI, R. 2007. Effects of freezing and thawing on the quality changes of tiger shrimp (Penaeus monodon) frozen by air-blast and cryogenic freezing. J. Food Eng. 80(1): 292-299.

FREDRICK, S. J., IMMACULATE, J. K., PATTERSON, E. J. K. 2015. Aflatoxins investigations on dried fishes of Tuticorin, Southeast Coast of India. J. Foodborne Zoonotic Dis. 3(4): 49-62.

LEE, M. H., HWANG, S. M., SUH, M. K., HA, G. Y., KIM, H. and PARK, J. Y. 2012. Onychomycosis caused by Scopulariopsis brevicaulis: report of two cases. Ann. Dermatol. 24(2): 209-213.

SIKDER, M. M., MALLIK, M. R. I. and ALAM, N. 2019. Identification and in vitro growth characteristics of entomopathogenic fungus-Aschersonia sp. in Bangladesh. Advances in Zoology and Botany. 7(1): 11-18.

TAMURA, K., STECHER, G., PETERSON, D. FILIPSKI, A. KUMAR, S. 2013. MEGA6: Molecular evolutionary genetics analysis version 6.0. Mol. Biol. Evol. 30: 2725-2729.

(Manuscript received on 14 May, 2020 revised on 13 June, 2020) 